\title{
EFEITOS DELETÉRIOS DO AGROTÓXICO CIPERMETRINA NA MICROBIOTA HUMANA, COM BASE NA INGESTÃO DIÁRIA ACEITÁVEL (IDA)
}

\author{
S. H. P. RIBEIRO ${ }^{1}$, G. A. CAVALCANTE ${ }^{3}$, C. A. CHAGAS $^{2}$, I. S. OLIVEIRA ${ }^{1}$, \\ ${ }^{1}$ Universidade Federal de Pernambuco, Centro Acadêmico de Vitória, Núcleo de Enfermagem \\ ${ }^{2}$ Universidade Federal de Pernambuco, Centro Acadêmico de Vitória, Núcleo de Ciências \\ Biológicas. \\ ${ }^{3}$ Universidade Federal de Pernambuco, Programa de Pós-Graduação em Ciências Biológicas \\ E-mail para contato: sarana_pereira@hotmail.com
}

\begin{abstract}
RESUMO - A microbiota humana desempenha importante papel no processo saúde e doença. No entanto, não se conhece o efeito de agrotóxico frente a esse imenso microbioma, apenas os efeitos toxicológicos frente às células humanas. Desta forma, o objetivo do trabalho foi avaliar o efeito microbicida de Cipermetrina, determinando a concentração inibitória mínima (CIM) frente a algumas espécies de bactérias (Staphylococcus aureus, S. epidermidis e Escherichia coli) e fungos (Candida sp.) representantes da microbiota da pele e intestino, partindo do valor da ingestão daria aceitável (IDA) liberada pela ANVISA. Foram realizados ensaios in vitro de microdiluição em caldo para bactérias e fungos, em microplacas de 96 poços. Os resultados mostraram que tanto para as espécies de bactérias quanto as leveduras, a CIM $(0,03 \mathrm{mg} / \mathrm{ml})$ ficou bem abaixo da IDA (3mg para pessoa com 60kg), cerca de 10x menos. Esses resultados sugerem que apesar da IDA ser uma dose de segurança toxicológica para células humanas, é um valor perigoso para o equilibrio da microbiota humana, podendo comprometer sua funcionalidade.
\end{abstract}

Palavras-chave: intestino, pele, bactéria, levedura, pesticida

ABSTRACT - The human microbiota plays important role in health and disease process. However, no known effect of pesticide in the face of this immense microbioma, only toxicological effects to human cells. Thus, the main of this paper was to evaluate the effect of microbicide Cypermethrin, determining the minimum inhibitory concentration (MIC) in front of some species of bacteria (Staphylococcus aureus, S. epidermidis and Escherichia coli) and fungi (Candida sp.) representatives of skin and gut microbiota, give acceptable intake value (IDA) released by ANVISA. Were carried out in vitro assays of microdilution in broth for bacteria and fungi, in microplates of 96 wells. The results showed that both species of bacteria as the yeasts, CIM $(0,03 \mathrm{mg} / \mathrm{ml})$ was well below the IDA $(3 \mathrm{mg}$ to person with $60 \mathrm{~kg}$ ), about $10 x$ less. These results suggest despite IDA be a dose of toxicological safety to human cells, is dangerous for the balance of the human 
microbiota, and can compromise your functionality.

Keywords: intestine, skin, bacteria, yeast, pesticide

\section{INTRODUÇÃO}

A microbiota humana desempenha funções diversas e indispensáveis à manutenção da saúde humana. O microbioma intestinal influencia de forma vital a maneira como funciona o trato gastrointestinal, assim como age na modulação do sistema imunológico e outras funções, tais como a sinalização entre células neuro-endócrinas e comunicação no conjunto designado como eixo cérebro-intestino (ZORZO, 2017). No ser humano saudável o microbioma mantém-se estável e estabelece com o hospedeiro uma indispensável relação simbiótica (SCHOLTENS, 2012). Esse vasto ecossistema (microbiota intestinal) tem sido considerado como um "novo órgão", visto a grande importância no funcionamento adequado do organismo humano (AZIZ et al., 2013). Estima-se que no intestino humano estejam presentes cerca de 100 trilhões de microrganismos, entre fungos, bactérias e vírus (GAGNIERE et al., 2016). Variações no ambiente microbiológico do intestino interferem na manutenção da homeostasia, desfazendo o equilíbrio entre hospedeiro e microbiota (NISTAL et al, 2015). Juntamente com o intestino, a pele compõe a maior microbiota do corpo humano, sendo menos diversificada que a microbiota intestinal (Grice; Segre, 2011)

Um importante fator contribuinte nas variações do microambiente intestinal é a alimentação com resíduos de agrotóxicos. O Brasil tem se estabelecido como o maior consumidor de agrotóxicos do mundo, avançando proporcional ao avanço da produção agrícola do país (CARVALHO et al., 2017). Mesmo após o alerta emitido por Rachel Carson, com a publicação do livro "Primavera Silenciosa" em 1962, o mundo continua em ascensão de produção de pesticidas, tendo em vista a alta rentabilidade gerada pelo setor agrícola.

No Brasil, a regulação de consumo de pesticidas é de responsabilidade da Agência Nacional de Vigilância Sanitária (ANVISA), que tem estabelecido níveis de alerta, como a classificação quanto à toxicidade, como também doses seguras para ingestão máxima no período de um dia (Ingestão Diária Aceitável - IDA). Estas informações constam nas fichas técnicas dos agrotóxicos. A Cipermetrina é um agrotóxico do grupo dos piretroides, classificado como "altamente tóxico", sua IDA corresponde ao valor de $0,05 \mathrm{mg} / \mathrm{kg}$ de peso corporal (ANVISA, 2010). Tendo em vista as informações já mencionadas, o objetivo deste trabalho foi avaliar in vitro os efeitos deletérios do agrotóxico Cipermetrina frente a bactérias da microbiota humana (intestinal e pele), com base na IDA liberada pela ANVISA. Os fatos supramencionados relatam a grande relevância deste estudo, considerando o fato da IDA definida com base em ensaios toxicológicos frente a células humanas, mas sem levar em consideração a incontestável importância das funções desempenhadas pela microbiota humana e os consequentes prejuízos à saúde humana frente a disbiose gerada pelo consumo de agrotóxicos e sua possível ação deletéria ao microbioma humano. Desta forma, o trabalho é inovador e inédito.

\section{MATERIAIS E MÉTODOS}

\section{Microrganismos}

Utilizou-se espécies colonizadoras da microbiota humana, e consideradas padrão para testes in vitro para atividade antimicrobiana, sendo as bactérias (Escherichia coli, 
Staphylococcus aureus e Staphylococcus epidermidis) e fungos leveduriformes do gênero Candida (Candida albicans, C. tropicalis, C. krusei,), cepas clínicas e ATCC. Todos estes microrganismos são tipicamente colonizadores da microbiota humana e foram obtidos da coleção de culturas bacterianas do Departamento de Antibióticos da Universidade Federal de Pernambuco (UFPEDA) e micoteca da mesma instituição (UFPE).

\section{Agrotóxico Testado}

Utlizou-se o pesticida Cipermetrina, agrotóxico do grupo dos piretroides, classificado como "altamente tóxico", sendo testado em várias concentrações, incluindo sua IDA correspondente ao valor de $0,05 \mathrm{mg} / \mathrm{kg}$ de peso corporal (ANVISA, 2010) para determinar a concentração inibitória mínima (CIM).

\section{Determinação da Concentração Inibitória Mínima (CIM)}

O teste de atividade antimicrobiana para determinação da CIM foi conduzido segundo procedimento da norma técnica da ANVISA M7-A6 Metodologia dos Testes de Sensibilidade a Agentes Antimicrobianos por Diluição para Bactéria de Crescimento Aeróbico: Norma Aprovada - CLSI (Clinical and Laboratory Standards Institute), e também realização da norma técnica M27-A2 para Testes de Diluição em Caldo para Determinação da Sensibilidade de Leveduras à Terapia Antifúngica em triplicata.

Foram distribuídos $80 \mu \mathrm{L}$ de meio de cultura (caldo Müeller-Hinton para os testes com bactéria e caldo Saboraud para as espécies fúngicas) nos poços-teste. Em seguida, adicionaram-se $80 \mu \mathrm{L}$ do agrotóxico no primeiro poço da fileira, já contendo meio de cultura. Realizou-se diluição seriada com fator de diluição 1:2. Em seguida, acrescentaram-se aos poços-teste $20 \mu \mathrm{L}$ da suspensão microbiana. A suspensão de microrganismos foi preparada em solução salina a $0,9 \%$, usando a escala padrão de Mac Farland correspondente ao tubo 0,5 que contém $1,5 \times 10^{8} \mathrm{ufc} / \mathrm{mL}$. Desta suspensão, foi preparada diluição 1:100 com salina estéril. Para controle de crescimento microbiano, foi utilizado meio de cultura e suspensão microbiana. Como controles de atividade positiva contra bactérias foi usado antibiótico (clorafenicol $-0,005 \mathrm{mg} / \mathrm{mL}$ ) e para as leveduras, antifúngico (fluconazol $-1 \mathrm{mg} / \mathrm{mL}$ ) $\mathrm{O}$ poço-controle foi meio de cultura adicionado de cipermetrina. Os testes foram realizados em triplicata e revelados com $30 \mu \mathrm{L}$ de solução de Resazurina a 0,01\% (para as bactérias), e com $40 \mu \mathrm{L}$ de cloreto de 2,3,5 Trifeniltetrazólio (TTC), após tempo de incubação de crescimento de $24 \mathrm{~h}$ à temperatura de $37^{\circ} \mathrm{C}$. Após $2 \mathrm{~h}$ de incubação com os corantes foram realizadas as leituras. Nos poços onde as amostras não apresentam ação antimicrobiana, ocorre a formação da coloração vermelha.A concentração inibitória mínima (CIM) corresponde à menor concentração capaz de inibir completamente o crescimento microbiano nos poços via leitura a olho nu (CLSI, 2012), ao passo que a concentração bactericida mínima (CBM) é a menor concentração em que o composto apresenta ação bactericida (BARON e FINEGOLD, 1990). O uso do TTC dispensa a necessidade de inoculação do conteúdo dos poços onde foi obtida a CIM, uma vez que este demonstra de forma satisfatória em que poços ainda estão presentes células viáveis, e, portanto tanto a CIM como a CBM foram determinadas mediante uso do referido corante vital. 


\section{RESULTADOS E DISCUSSÃO}

Nos testes realizados neste estudo, Cipermetrina mostra capacidade microbicida ao matar bactérias e fungos da microbiota humana em baixíssimas concentrações. Resultados dos ensaios desta pesquisa evidenciam CIM de $0,03 \mathrm{mg} / \mathrm{mL}$ frente às três espécies de bactérias utilizadas nos testes (E. coli, S. aureus, S. epidermidis) e a mesma concentração inibitória mínima média de $0,03 \mathrm{mg} / \mathrm{mL}$ para quatro das espécies de leveduras do gênero Candida $(C$. albicans, C. krusei, C. tropicalis, C. parapsilosis). A menor CIM estabelecida foi para $C$. guilliermond $(0,01 \mathrm{mg} / \mathrm{mL})$. A tabela 1 mostra os resultados descritos acima.

Tabela 1 - Concentração Inibitória Mínima de Cipermetrina para espécies bacterianas e fúngicas da microbiota humana.

\begin{tabular}{llll}
\hline \multicolumn{1}{c}{ Leveduras } & \multicolumn{1}{c}{ CIM } & \multicolumn{1}{c}{ Bactérias } & \multicolumn{1}{c}{ CIM } \\
\hline C. albicans & $0,03 \mathrm{mg} / \mathrm{mL}$ & E. coli & $0,03 \mathrm{mg} / \mathrm{mL}$ \\
C. krusei & $0,03 \mathrm{mg} / \mathrm{mL}$ & S. aureus & $0,03 \mathrm{mg} / \mathrm{mL}$ \\
C. tropicalis & $0,03 \mathrm{mg} / \mathrm{mL}$ & S. epidermidis & $0,03 \mathrm{mg} / \mathrm{mL}$ \\
C. parapsilosis & $0,03 \mathrm{mg} / \mathrm{mL}$ & & \\
C. guilliermond & $0,01 \mathrm{mg} / \mathrm{mL}$ & & \\
\hline
\end{tabular}

Enfatiza-se que a unidade da IDA é "mg/kg p. c.", ou seja, de acordo com a IDA, para um indivíduo de $60 \mathrm{~kg}$ de peso corporal, é aceitável a ingestão de $3 \mathrm{mg}$ do agrotóxico Cipermetrina por dia. Para uma criança de $20 \mathrm{~kg}$ de peso corporal, é aceitável (segundo a IDA) a ingestão de $1 \mathrm{mg}$ de Cipermetrina por dia. Enquanto que de acordo com a CIM estabelecida nos ensaios in vitro deste estudo, $0,03 \mathrm{mg}$ de Cipermetrina é uma concentração alta o suficiente para matar bactérias e fungos leveduriformes da microbiota da pele e intestino, num valor equivalente mínimo de $1,5 \times 10^{5} \mathrm{ufc} / \mathrm{mL}$. O gráfico 1 mostra os valores das doses da IDA e a CIM, exemplificando indivíduos hipotéticos.

Gráfico 1 - Valor da Ingestão Diária Aceitável (IDA) e Concentração Inibitória Mínima (CIM) de Cipermetrina em pessoas com 30, 60 e $90 \mathrm{~kg}$ de peso corporal.

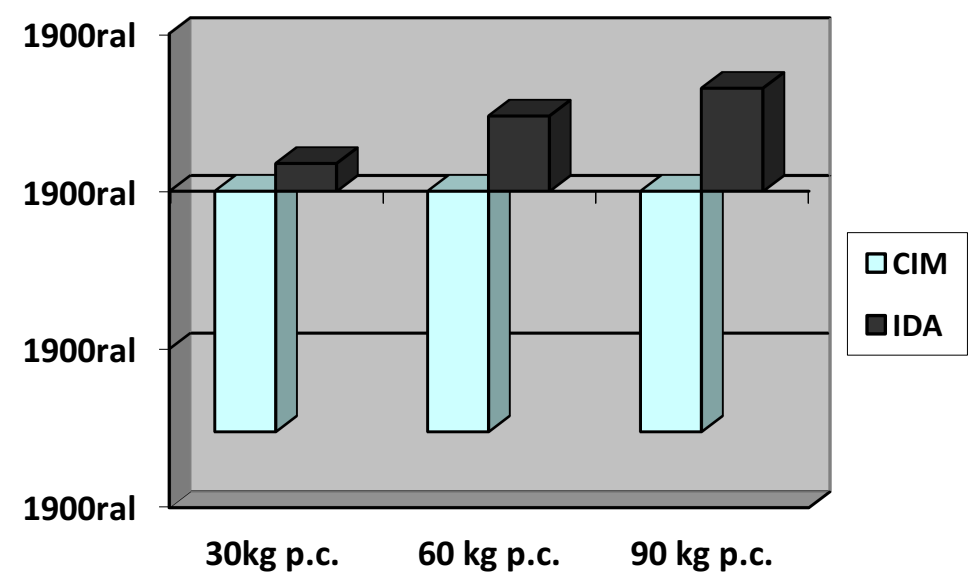

Legenda: Eixo do x - concentrações de cipermetrina. Eixo de $\mathrm{Y}$ - peso corporal de pessoas com 30,60 e $90 \mathrm{~kg}$. 
Ao observar o gráfico 1 fica evidente ao comparar as doses estabelecidas nos testes que a IDA de Cipermetrina liberada pela ANVISA encontra-se bem acima da CIM, sendo portanto um valor permitido perigoso quanto à conservação do microbioma humano da pele $\mathrm{e}$ intestino. Sendo importante ampliar as espécies do microbioma humano a serem estudadas. Os microrganismos componentes da microbiota humana desempenham funções indispensáveis e as mais variadas. A interferência em sua população acarreta o efeito negativo na homeostase corporal, no funcionamento do sistema nervoso entérico, do sistema imune local, na influência no sistema nervoso central (vários fatores, incluindo os comportamentais). Para o efetivo processo digestivo há a participação de microrganismos que desempenham funções que servem para melhor aproveitamento de nutrientes, dos quais o ser humano não está dotado (FIOCCHI, SOUZA 2012). A microbiota age, ainda, no estímulo do SNA simpático, secreção mucosa de serotonina, influencia positivamente na memória e na capacidade de aprendizado (CARABOTTI et al., 2015). Em síntese, alterar a composição do microbioma humano significa interferir negativamente em vários processos da fisiologia humana que dependem da colaboração de microrganismos benéficos, que vivem em relação simbiótica com o homem. Sendo assim, há uma urgência em se estudar e ampliar os teste inicialmente in vitro sobre ação deletéria de agrotóxicos frente a mais espécies do microbioma humano.

\section{CONCLUSÃO}

Os dados resultantes deste estudo evidenciam que a IDA do agrotóxico Cipermetrina foi estabelecida em doses consideravelmente altas com ação deletéria para o microbioma humano da pele e intestino, sendo portanto a IDA potencialmente geradora de disbiose, condição que associa-se ao surgimento de diversas patologias. Com a interpretação destes resultados, sugere-se a reconsideração do valor atual da IDA de Cipermetrina, a fim de minimizar os danos que o uso deste pesticida pode acarretar na microbiota da pele e intestino.

\section{REFERÊNCIAS}

ANVISA Resolução RE n ${ }^{\circ} 2.953$ de 28/06/10 (DOU de 05/07/10)

AZIZ Q., DORE J., EMMANUEL A., GUARNER F., QUIGLEY E.M. Gut microbiota and gastrointestinal health: current concepts and future directions. Neurogastroenterology and motility : the official journal of the European Gastrointestinal Motility Society. 2013; 25(1):415.

CARABOTTI, M.; SCIROCCO, A.; MASELli, M. A.; SEVERI, C. Annals Gastroenterologia. v. 28, n. 2, p. 203-209. 2015

CLSI. Methods for dilution antimicrobial susceptibility tests for bacteria that grow aerobically - M7-A6. 6. ed. CLSI, Wayne: USA, 2003. 
CLSI. Método de referência para testes de diluição em caldo para a determinação da sensibilidade a terapia antifúngica das leveduras - M27-A2. 2. ed. CLSI, Wayne: USA, 2002 .

FIOCCHI C, SOUZA HSP. Microbiota Intestinal: Sua importância e função. Jor. Bras. de Medicina. 2012 julho/agosto; 100:30-8

GAGNIERE J, RAISCH J, VEZIANT J, BARNICH N, BONNET R, BUC E, et al. Gut microbiota imbalance and colorectal cancer. World journal of gastroenterology. 2016; 22(2):501-18.

GRICE, E A.; SEGRE, J A . The skin micrbiome. Nat Ver. Microbiol. 2011; 9(4): 244-253.

NISTAL E, FERNANDEZ-FERNANDEZ N, VIVAS S, OLCOZ JL. Factors Determining Colorectal Cancer: The Role of the Intestinal Microbiota. Frontiers in oncology. 2015; 5:220.

ZORZO, Renato Augusto. Impacto do microbioma intestinal no Eixo CérebroIntestino. International Journal of Nutrology, v. 10, n. 1, p. 298-305, 2017.

\section{AGRADECIMENTOS}

Os autores agradecem a CAPES pela concessão da bolsa de pós-graduação. 